\title{
Mitochondrial sequences reveal a clear separation between Angolan and South African giraffe along a cryptic rift valley
}

Friederike Bock', Julian Fennessy ${ }^{2,3^{*}}$, Tobias Bidon ${ }^{1}$, Andy Tutchings ${ }^{2}$, Andri Marais ${ }^{2}$, Francois Deacon 2,4 and Axel Janke ${ }^{1,5}$

\begin{abstract}
Background: The current taxonomy of the African giraffe (Giraffa camelopardalis) is primarily based on pelage pattern and geographic distribution, and nine subspecies are currently recognized. Although genetic studies have been conducted, their resolution is low, mainly due to limited sampling. Detailed knowledge about the genetic variation and phylogeography of the South African giraffe (G. C. giraffa) and the Angolan giraffe (G. C. angolensis) is lacking. We investigate genetic variation among giraffe matrilines by increased sampling, with a focus on giraffe key areas in southern Africa.

Results: The 1,562 nucleotides long mitochondrial DNA dataset (cytochrome b and partial control region) comprises 138 parsimony informative sites among 161 giraffe individuals from eight populations. We additionally included two okapis as an outgroup. The analyses of the maternally inherited sequences reveal a deep divergence between northern and southern giraffe populations in Africa, and a general pattern of distinct matrilineal clades corresponding to their geographic distribution. Divergence time estimates among giraffe populations place the deepest splits at several hundred thousand years ago.

Conclusions: Our increased sampling in southern Africa suggests that the distribution ranges of the Angolan and South African giraffe need to be redefined. Knowledge about the phylogeography and genetic variation of these two maternal lineages is crucial for the development of appropriate management strategies.
\end{abstract}

Keywords: Giraffa, Angolan giraffe, South African giraffe, Population genetics, Botswana, Namibia, Phylogeny, mtDNA

\section{Background}

For more than 250 years, giraffe (Giraffa camelopardalis) taxonomy has attracted interest among scientists [1-3]. The descriptions of the nine giraffe subspecies are primarily based on pelage patterns, characteristics of ossicones and their geographic distribution across the African continent $[4,5]$. However, the inconsistent pelage recognition has confused taxonomical assignments due to its high variability [6-8]. Recent efforts using molecular genetic techniques are beginning to clarify giraffe taxonomy [9-11]. In contrast to studies on elephant $[12,13]$, and other African

\footnotetext{
* Correspondence: julian@giraffeconservation.org

${ }^{2}$ Giraffe Conservation Foundation, 26 Grasmere Road, Purley, Surrey CR8 1DU, England

${ }^{3}$ School of Biological Earth and Environmental Studies (BEES), University of New South Wales (UNSW), Sydney, New South Wales 2052, Australia Full list of author information is available at the end of the article
}

wildlife [14,15], a range-wide genetic analysis of giraffe is lacking [9-11]. A phylogenetic study using data of six subspecies (Angolan giraffe (G. c. angolensis), South African giraffe (G. c. giraffa), West African giraffe (G. c. peralta), reticulated giraffe (G. c. reticulata), Rothschild's giraffe (G. c. rothschildi) and Masai giraffe (G. c. tippelskirchi)) based on nuclear microsatellites and mitochondrial $(\mathrm{mt})$ DNA sequences suggested that some of the subspecies may actually represent distinct species [9]. Another study of the giraffe subspecies historically classified as Thornicroft's giraffe (G. c. thornicrofti), which is restricted to Zambia's South Luangwa valley, showed that this population has a distinct mtDNA haplotype that is nested within the clade of Masai giraffe [11]. Genetic analysis suggested that the Kordofan giraffe (G. c. antiquorum) in Central Africa is closely related to the West African giraffe [10], while the relationship of 
the Nubian giraffe (G. c. camelopardalis) is unclear due to a lack of any genetic analyses.

In southern Africa, two subspecies of giraffe live in close proximity. South African giraffe have been reported to occur naturally throughout southern Botswana, southern Zimbabwe, southwestern Mozambique, northern South Africa and southeastern Namibia [7]. Giraffe of northwestern and north-central Namibia have been categorized as Angolan giraffe $[1,16]$ but the taxonomic classification of giraffe from northern Botswana and northeastern Namibia remains uncertain. Angolan giraffe is thought to occur also in southern Zambia, western Zimbabwe and central Botswana [16]. Both giraffe populations have historically been classified as either G. c. giraffa or G. c. angolensis, or most recently as a hybrid of $G$. giraffa/G. angolensis, depending on the taxonomic reference $[6,8]$. The uncertainty of giraffe taxonomy in southern Africa affects conservation efforts, as individuals are being translocated both within and between different populations and countries across Africa without knowledge of the taxonomical status. Frequently, these translocations are driven by economic reasons for improving regional tourism rather than biodiversity conservation [17]. Conservation policies depend on reliable information about the taxonomic status and about genetic variability of locally adapted populations. Clarifying the relationship and distribution of the Angolan and South African giraffe is therefore particularly relevant for conservation efforts of the newly established KavangoZambezi Transfrontier Conservation Area (KAZA) that includes northeastern Namibia and northern Botswana.

Although no targeted census of giraffe has been conducted, the size of Botswana's northern giraffe population is estimated to have dropped over the last decade from $>10,000$ to $<4,000$ individuals [18]. The number of giraffe in Bwabwata National Park in Namibia was decimated in the 1970s and 1980s due to illegal hunting but has recovered since then to $>150$ individuals [19].

We here present a population genetic analysis of mitochondrial cytochrome b (cytb) and partial control region (CR) sequences for eight of the nine currently described giraffe subspecies. Our sampling focuses on geographic regions that have not been analyzed before, particularly in southern Africa: Namibia (Bwabwata National Park BNP, Etosha National Park - ENP) and Botswana (Chobe National Park - CNP, Moremi Game Reserve MGR, Nxai Pans - NXP, Vumbura Concession - V, Central Kalahari Game Reserve - CKGR), but also central Africa's Democratic Republic of Congo (Garamba National Park GNP) (Table 1, Additional file 1: Table S1). Our dense sampling includes many key areas of the giraffe distribution range in southern Africa and therefore allows for a high-resolution analysis of the phylogeography of South African and Angolan giraffe. Furthermore, it allows assessing the impact of a "cryptic" rift valley, which runs northeast to southwest across Botswana from Zambia $[20,21]$, potentially having acted as a barrier to giraffe dispersal.

\section{Results}

Mitochondrial DNA sequences from the cytochrome b (cytb) gene and partial control region (CR) were successfully amplified from all samples. The cytb alignment was 1,140 nucleotides (nt) long and showed no gaps or ambiguous sites. We also sequenced the L-strand of the CR for a length of 786/787 nt, excluding the highly repetitive poly-cytosine region. In order to match our newly obtained sequences with published data, the length of

Table 1 Origin, abbreviation, number of individuals $(N)$ and subspecies designation of analyzed giraffe sequences

\begin{tabular}{lllll}
\hline Geographic origin & Abbreviation & N & Previous subspecies designation & Subspecies designation (this study) \\
\hline Vumbura Concession, Botswana & V & 11 & angolensis & giraffa \\
Chobe National Park, Botswana & CNP & 11 & angolensis & giraffa \\
Bwabwata National Park, Namibia & BNP & 7 & angolensis & giraffa \\
Moremi Game Reserve, Botswana & MGR & 16 & angolensis & giraffa \\
Nxai Pans, Botswana & NXP & 1 & angolensis & giraffa \\
Garamba National Park, DR Congo & GNP & 3 & antiquorum & antiquorum \\
Zakouma National Park, Chad & ZNP & 1 & antiquorum & antiquorum \\
Central Kalahari Game Reserve, Botswana & CKGR & 7 & angolensis & angolensis \\
Etosha National Park, Namibia & ENP & 17 & angolensis & angolensis \\
Khamab Kalahari Reserve, South Africa & KKR & 6 & giraffa & giraffa \\
Niger & WA & 13 & peralta & peralta \\
Murchison Falls National Park, Uganda & MF & 9 & rothschildi & rothschildi \\
Luangwa Valley, Zambia & LVNP & 5 & thornicrofti & tippelskirchi \\
Selous Game Reserve, Tanzania & SGR & 6 & tippelskirchi & tippelskirchi \\
\hline
\end{tabular}


the CR alignment was limited to $422 \mathrm{nt}$. The stringent 422 nt CR alignment did not contain gaps. The CR was relatively conserved outside this 422 nt region and until the poly-cytosine sequence, yielding only three variable sites among 20 giraffe individuals that represented all clades. All sequences conformed to the reading frame, length, stop codon and other properties of a functional protein coding gene or the control region that are observed in an established mitochondrial genome [EMBL: NC012100]. Sequences with the same properties were also obtained using the alternative primer pair for amplification and sequencing. Thus, it is reasonable to assume that no mitochondrial nuclear mitochondrial insertions (numts) were sequenced. The inclusion of two okapi (Okapia johnstoni) sequences introduced unambiguously placed gaps in the CR alignment, which were ignored in all subsequent analyses. The combined (cytb plus CR) alignment was 1,562 nt long and contained 138 parsimony informative sites. The alignment included 161 giraffe and two okapi individuals, of which 102 giraffe were newly sampled (Table 1, Additional file 1: Table S1).

The Bayesian analysis of mitochondrial sequence data recovered the matrilines of all giraffe subspecies to be monophyletic with respect to each other, although not all nodes received posterior support values above 0.95 (Figure 1). The most obvious pattern is a well-supported north-south split, with the southern subspecies Angolan giraffe, South African giraffe, and Masai/Thornicroft's giraffe being separated from the northern subspecies Kordofan giraffe, reticulated giraffe, Rothschild's giraffe and West African giraffe.

Using a molecular clock, BEAST estimates the deepest divergence time among giraffe matrilines between the northern and southern clade at ca. 2.0 million years ago (Ma) (Figure 2). This is followed by the divergence of a mtDNA clade containing Angolan giraffe, South African giraffe and Masai/Thornicroft's giraffe at ca. 1.4 Ma (Table 2, Figure 2). A northern giraffe clade, which includes the Kordofan giraffe, reticulated giraffe, Rothschild's giraffe, and West African giraffe, diverged at about $0.8 \mathrm{Ma}$ (Table 2). Divergences within each subspecies are estimated to have occurred between 100 to 400 thousand years (ka) ago. Note that the Bayesian posterior support values for some of the nodes at the subspecies level were below 0.95 (Figure 2).

Giraffe from Luangwa Valley National Park, Zambia, which are formally classified as Thornicroft's giraffe, form a uniform but not a separated matrilineal group within the variation of Masai giraffe. Note, that the divergence between the southern and northern clade occurs between populations south and north of the equator that are in close geographic proximity to each other (Masai giraffe, reticulated giraffe, Rothschild's giraffe). The relative clustering of the northern mtDNA clades (West African giraffe, Rothschild's giraffe, Kordofan giraffe and reticulated giraffe) remains uncertain due to low posterior support values for some of the nodes (Figure 1, Figure 2).

Nine database individuals that were assigned to a particular subspecies previously [9] grouped at unexpected positions in our phylogenetic analysis (numbered individuals in Figure 1). Two individuals of South African giraffe (\# 1 and 2) are placed within Angolan giraffe but not with other South African giraffe individuals. Likewise, two individuals (\# 3 and 4) of Masai giraffe are placed within South African giraffe, two Rothschild's giraffe individuals (\# 5 and 6) grouped with Masai giraffe, one Masai giraffe (\# 7) fell basal to reticulated giraffe, and two reticulated giraffe (\# 8 and 9) grouped with Rothschild's giraffe. Additional information of the geographic origin of each individual sequence is given in Additional file 1: Table S1.

Currently, there are four giraffe subspecies recognized south of the equator in Africa: Masai/Thornicroft's giraffe, South African giraffe, and Angolan giraffe, the two latter occurring in close proximity in Botswana. In our data, Angolan giraffe individuals from the Central Kalahari Game Reserve in central Botswana grouped with Angolan giraffe from the Etosha National Park in Namibia, which was expected from their geographic origin and previously assumed classification. One individual from the Etosha National Park fell into the Central Kalahari Game Reserve mtDNA clade.

Unexpectedly, 46 individuals sampled as Angolan giraffe from Chobe National Park, Nxai Pans, Vumbura Concession and Moremi Game Reserve in northern Botswana, and Bwabwata National Park in northeastern Namibia grouped with South African giraffe from the Khamab Kalahari Reserve in South Africa. These hitherto not sampled regions thus harbor mtDNA lineages of the South African giraffe subspecies and not of Angolan giraffe. Populations carrying the mitochondrial haplotype of South African giraffe thus geographically enclose the Angolan giraffe of the Central Kalahari Game Reserve from the north and south (Figure 3).

Individuals from Bwabwata National Park formed a separate group with its own mtDNA haplotype (Figure 1, Figure 4).

To assess differentiation between populations, pairwise $\mathrm{F}_{\mathrm{ST}}$ values were calculated (Table 3 ). The overall population differentiation of mtDNA was high, with $\mathrm{F}_{\mathrm{ST}}$ values ranging from 0.672 (Masai giraffe and Thornicroft's giraffe) to 0.998 (Rothschild's giraffe and Thornicroft's giraffe). The pairwise $\mathrm{F}_{\mathrm{ST}}$ value between South African and Angolan giraffe was 0.929, showing a clear differentiation between those two populations, despite their close geographic proximity.

A haplotype network analysis supports the strong divergences among most giraffe mtDNA clades (Figure 4), 
Figure 1 Phylogenetic tree based on mitochondrial DNA encompassing 161 giraffe individuals. The topology corresponds to a maximum clade credibility tree obtained from BEAST, but branch lengths were calculated by maximum likelihood in Treefinder. Each dot represents one individual giraffe, colors are coding for the respective subspecies/population. " $z$ " denotes captive (zoo) individuals, asterisks at branches indicate Bayesian posterior support $>0.95$. Abbreviations for the samples are explained in the text and in Table 1.

as sub-networks representing the different subspecies are not connected to each other at the $95 \%$ connection probability limit. Corresponding to our phylogenetic analysis (Figure 1), Thornicroft's giraffe are an exception, as individuals from the Luangwa valley share a distinct haplotype that falls within the variation of Masai giraffe. The networks also demonstrate the considerable amount of variation within most subspecies: Masai/Thornicroft's and Angolan giraffe have the highest numbers of haplotypes (14 and 13, respectively; Table 4). Kordofan and reticulated giraffe show the highest haplotype diversities, $0.964 \pm 0.077$ and $0.972 \pm 0.064$, respectively - almost every individual has its own mitochondrial haplotype. In contrast, Thornicroft's, West African and Rothschild's

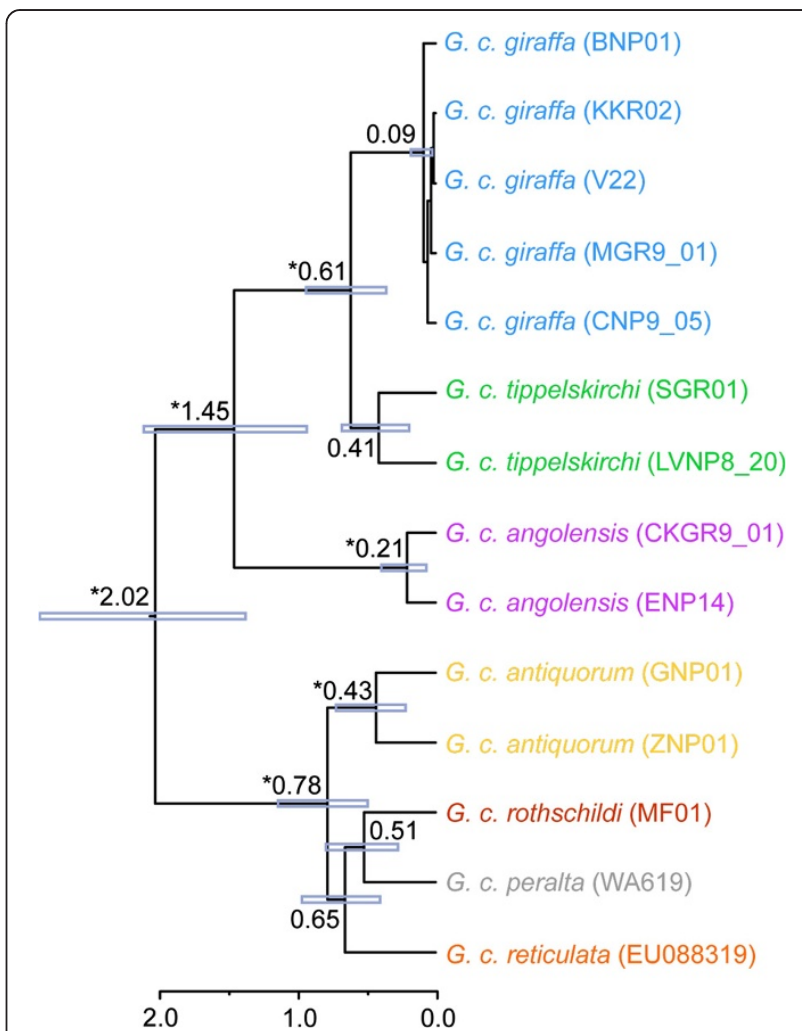

Figure 2 Maximum clade credibility tree of the major giraffe populations as reconstructed by Bayesian analysis conducted in BEAST. Blue bars indicate 95\% highest posterior density intervals for node ages, asterisks denote posterior probability $>0.95$. Scale on the bottom represents divergence time (million years ago). 
Table 2 Divergence time estimates (median heights and 95\% highest posterior density intervals) obtained from BEAST based on 1,565 nt mtDNA

\begin{tabular}{ll}
\hline Divergence & $\begin{array}{l}\text { Time estimate } \\
\text { (Ma) }\end{array}$ \\
\hline $\begin{array}{l}\text { G. c. giraffa plus tippelskirchi plus angolensis vs. } \\
\text { antiquorum plus rothschildi plus peralta plus reticulata }\end{array}$ & $2.0(1.4-2.8)^{*}$ \\
G. c. giraffa plus tippelskirchi vs. angolensis & $1.4(0.9-2.1)^{*}$ \\
G. c. giraffa vs. tippelskirchi & $0.6(0.4-0.9)^{*}$ \\
G. c. giraffa & $0.1(0.02-0.2)$ \\
G. c. tippelskirchi & $0.4(0.2-0.7)$ \\
G. c. angolensis & $0.2(0.1-0.4)^{*}$ \\
G. c. antiquorum vs. rothschildi plus peralta plus & $0.8(0.5-1.1)^{*}$ \\
reticulata & \\
G. c. rothschildi plus peralta vs. reticulata & $0.7(0.4-1.0)$ \\
G. c. rothschildi vs. peralta & $0.5(0.3-0.8)$ \\
G. c. antiquorum & $0.4(0.2-0.7)^{*}$ \\
\hline Asteisks
\end{tabular}

Asterisks indicate posterior probability $>0.95$.

giraffe have the lowest number of haplotypes, the lowest haplotype diversity, and the lowest nucleotide diversity (Table 4), corresponding to the short branch lengths of these three mtDNA clades (Figure 1). Although the overall mitochondrial variation in South African giraffe was comparable to that of other clades (13 haplotypes, $\mathrm{H}_{\mathrm{d}}=0.769 \pm 0.050$; Table 4), it is noteworthy that one haplotype was common and shared among individuals from different reserves or parks (Vumbura Concession,
Chobe National Park, Moremi Game Reserve, Nxai Pans, all in Botswana) (Figure 4).

Rothschild's giraffe, which is currently considered "endangered" on the IUCN Red List [22], has two haplotypes among 11 individuals and low nucleotide and haplotype diversity $(0.00012 \pm 0.00009$ and $0.182 \pm 0.144$, respectively; Table 4).

\section{Discussion}

The analyses of 1,562 nt of concatenated mitochondrial sequence data identified seven well-separated and reciprocally monophyletic giraffe clades. The deepest divergence, as estimated by a Bayesian BEAST analysis, was found between a northern clade, comprising West African, Kordofan, reticulated, and Rothschild's giraffe, and a southern clade, comprising Angolan, South African, and Masai/Thornicroft's giraffe, despite the close geographic proximity of populations of both clades in East Africa. Notably, Masai giraffe are geographically much closer to northern populations than to the southern African Angolan and South African giraffe. The matrilineal clades identified are largely congruent to previously named subspecies and reflect the geographic structure seen among giraffe.

The Thornicroft's giraffe has been described to only occur in the Luangwa Valley National Park. Divergences between Thornicroft's and Masai giraffe are shallow, which is why the former was proposed to be subsumed into the Masai giraffe's clade [11]. These lineages are on

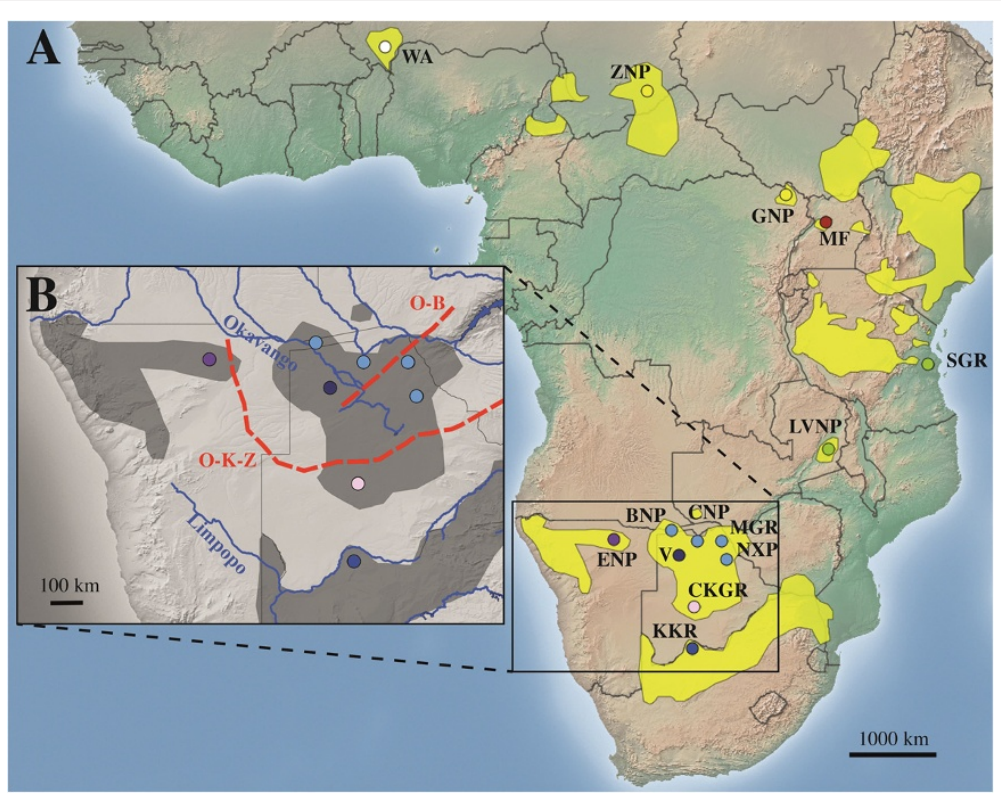

Figure 3 Map of sub-Saharan Africa. A: Distribution range of giraffe (yellow patches) and sampling locations (abbreviations are explained in Table 1). Colors show genetically identified subspecies (coding as in Figure 1). B: Depiction of southern African giraffe populations and location of geographic boundaries. O-K-Z: Owambo-Kalahari-Zimbabwe epigeiric axis, O-B: Okavango-Bangweulu axis. 


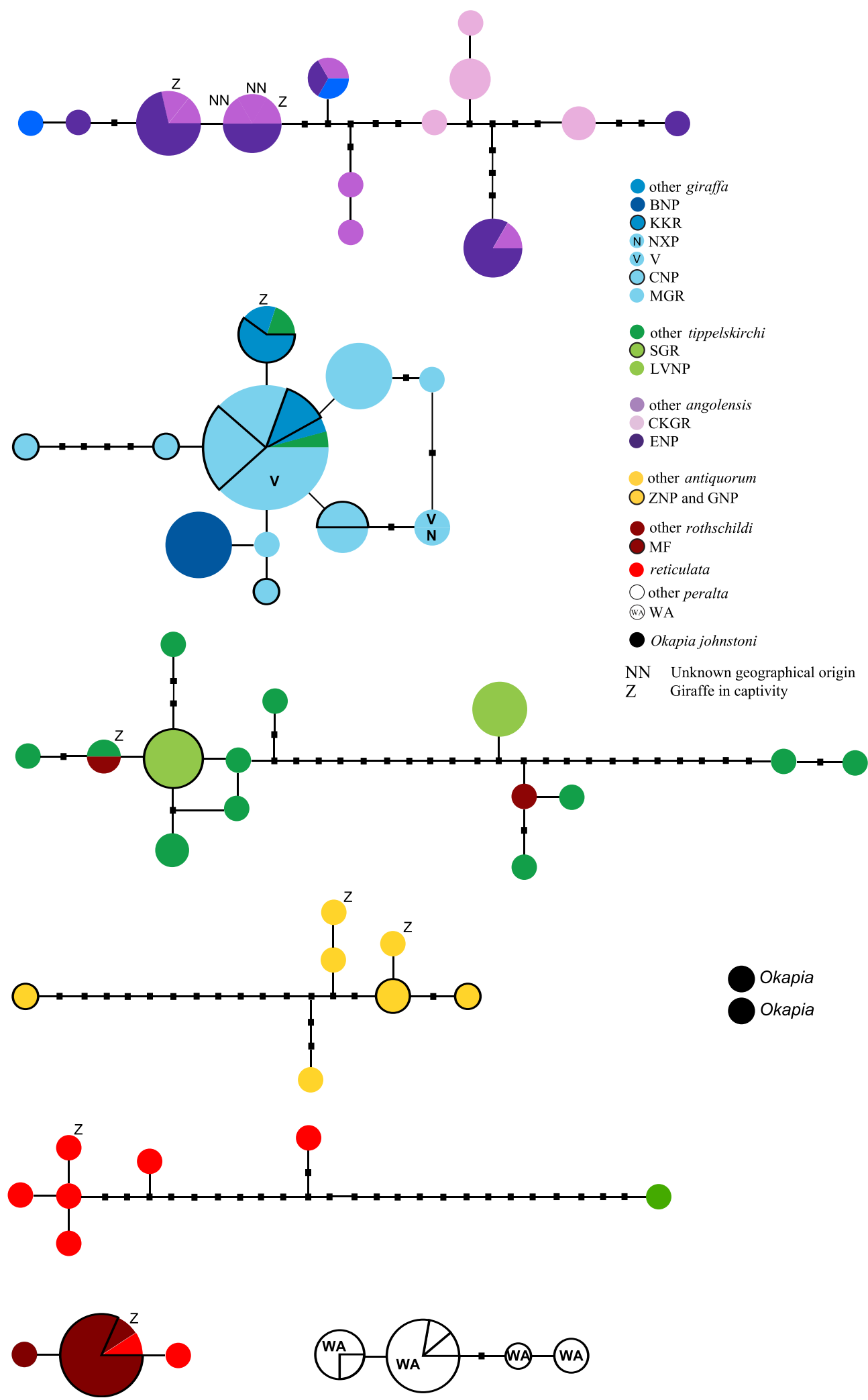

Figure 4 Statistical parsimony haplotype network of the giraffe and okapi sequences. The sub-networks of different giraffe subspecies do not connect at the $95 \%$ connection probability limit. Different populations having identical haplotypes are indicated by pie-sections. Black rectangles indicate not sampled haplotypes. Abbreviations as in Table 1. 
Table 3 Genetic differentiation (pairwise $\mathrm{F}_{\mathrm{ST}}$ values) among the eight subspecies as defined by mtDNA clades

\begin{tabular}{|c|c|c|c|c|c|c|c|}
\hline & angolensis & giraffa & peralta & antiquorum & thornicrofti & tippelskirchi & reticulata \\
\hline giraffa & 0.940 & & & & & & \\
\hline peralta & 0.935 & 0.978 & & & & & \\
\hline antiquorum & 0.905 & 0.967 & 0.859 & & & & \\
\hline thornicrofti & 0.897 & 0.935 & 0.984 & 0.930 & & & \\
\hline tippelskirchi & 0.859 & 0.838 & 0.916 & 0.866 & 0.506 & & \\
\hline reticulata & 0.901 & 0.961 & 0.839 & 0.689 & 0.900 & 0.856 & \\
\hline rothschildi & 0.938 & 0.980 & 0.959 & 0.887 & 0.996 & 0.918 & 0.842 \\
\hline
\end{tabular}

For assignment to mtDNA clades see Figure 1. All pairwise $F_{S T}$ values were highly significant $(p<0.001)$ when testing with 1,000 permutations.

discrete evolutionary trajectories, due to their geographic isolation. The shallow divergence might thus reflect retention of ancestral polymorphisms, rendering mtDNA a marker with limited diagnostic resolution [23,24]. However, the giraffe from Luangwa Valley National Park have a unique mitochondrial haplotype (Figure 4). This should be taken into account in giraffe conservation and management, in particular for ecological, spatial and behavioral aspects. A previously suggested placing of the South African giraffe within the variation of the Masai giraffe [9] could not be confirmed. Our mtDNA tree shows the same topology as found by Hassanin and colleagues [10].

Assignment of individual giraffe to the wrong subspecies is not unusual and could be explained by natural migration or human-induced translocation. It is noteworthy, however, that every single one of the newly sampled 102 individuals was associated with the expected subspecies. Therefore, our data do not indicate largescale migration of females from one subspecies to another or confusion of populations by human-induced translocation of females. Our new sampling effort of 102 individuals from well-defined areas and populations, and the data analyses indicate that individuals previously assigned to a clade different from the individual's designation [9] might be a result of mtDNA introgression, or of inadequate subspecies identification. This highlights the importance of accurate sample collection and identification.

From previous studies [2] and historical assumptions [6], it was expected that Botswana and Namibia contain Angolan giraffe, and that the South African giraffe occurs further south and east in South Africa and Zimbabwe $[2,6,25]$. However, our data suggest a narrow zone separating Central Kalahari Game Reserve in Botswana, which is inhabited only by Angolan giraffe, from Chobe National Park, Moremi Game Reserve, Nxai Pans Park, and Vumbura Concession in northern Botswana, which are inhabited by South African giraffe. The central and northwestern giraffe populations in Namibia have formerly been assigned to Angolan giraffe [1,16]. Based on our results, the Bwabwata National Park population in northeastern Namibia unambiguously represents South African giraffe. The Bwabwata National Park population is geographically close $(<100 \mathrm{~km})$ to Chobe National Park and Vumbura Concession (also inhabited by South African giraffe), whereas the nearest natural Angolan giraffe population is $>500 \mathrm{~km}$ to the west (Etosha National Park) or $>350 \mathrm{~km}$ to the south (Central Kalahari Game Reserve).

Pairwise $\mathrm{F}_{\mathrm{ST}}$ values of mtDNA sequences are expected to exceed those from nuclear markers in cases of strong

Table 4 Diversity indices per subspecies for the mtDNA

\begin{tabular}{lllllll}
\hline & $\mathbf{N}$ & $\mathbf{N}_{\mathbf{H}}$ & $\mathbf{H}_{\mathbf{d}}$ & $\mathbf{s d}\left(\mathbf{H}_{\mathbf{d}}\right)$ & $\mathbf{\pi}$ & $\mathbf{s d}(\boldsymbol{\pi})$ \\
\hline angolensis & $33(35)$ & $13(13)$ & $0.902(0.901)$ & $0.028(0.026)$ & $0.00351(0.00344)$ & $0.00026(0.00026)$ \\
antiquorum & 8 & $\mathbf{7}$ & 0.964 & 0.077 & 0.00434 & 0.00140 \\
giraffa & $56(56)$ & $13(11)$ & $0.769(0.751)$ & $0.050(0.052)$ & $0.00326(0.00103)$ & $0.00147(0.00017)$ \\
reticulata & $9(8)$ & $8(7)$ & $0.972(0.964)$ & $0.064(0.077)$ & $0.00800(0.00632)$ & $0.00209(0.00229)$ \\
rothschildi & $13(13)$ & $4(3)$ & $0.423(0.295)$ & $0.164(0.156)$ & $0.01171(0.00020)$ & $0.00589(0.00011)$ \\
thornicrofti & 5 & 1 & 0.000 & 0.000 & 0.00000 & 0.00000 \\
tippelskirchi & $21(20)$ & $15(13)$ & $0.924(0.911)$ & $0.050(0.054)$ & $0.01030(0.00555)$ & $0.00319(0.00119)$ \\
peralta & 16 & 4 & 0.642 & 0.103 & 0.00082 & 0.00022 \\
Total & $\mathbf{1 6 1}$ & $\mathbf{5 9}$ & $\mathbf{0 . 9 5 6}$ & $\mathbf{0 . 0 0 8}$ & $\mathbf{0 . 0 2 6 6 7}$ & $\mathbf{0 . 0 0 0 7 5}$ \\
\hline
\end{tabular}

$\mathrm{N}$ : number of analyzed individuals. $\mathrm{N}_{\mathrm{H}}$ : number of haplotypes. $\mathrm{H}_{\mathrm{d}}$ : haplotype diversity. sd: standard deviation. $\pi$ : uncorrected nucleotide diversity. All indices were calculated in DnaSP. For previously published sequences, the original subspecies assignments were used. Our own samples are assigned to subspecies according to their mtDNA clades in Figure 1. Numbers in brackets are the respective indices when the probably misassigned individuals \#1 to \#9 are put in the mtDNA clades as presented in Figure 1. 
female philopatry and male-biased gene flow or temporal nonequilibrium after a (recent) habitat fragmentation. In that case, mtDNA gene trees would show reciprocal monophyly and geographic structuring (as seen here), but nuclear loci would not support this [26].

The oldest fossils show that the giraffe species complex existed already about one Ma [27]. According to our divergence time estimates (Table 2, Figure 2), giraffe diverged into distinct populations that are designated as subspecies during the Pleistocene (2.6 Ma to $12 \mathrm{ka}$ ). This is considerably older than divergence times between closely related species of Ursus ( $600 \mathrm{ka})$ estimated by independently inherited nuclear introns [28], of Pan ( 420 ka) using multilocus analysis including mitochondrial, nuclear, X- and Y-chromosomal loci [29], or of Canis ( 900 ka) based on mitochondrial genes and nuclear loci [30]. Due to the lack of sequence data from giraffe fossils and closely related and dated outgroup fossils, our calibration points (5 and $9 \mathrm{Ma}$, respectively) might lead to an overestimation of divergence times within giraffe. However, the clear intraspecific structuring into region-specific maternal clades supports an early divergence within giraffe. However, the mitochondrial gene tree might differ from the species tree [31], and a multilocus approach will be necessary to estimate divergence times representative of the species as a whole. Support for the early divergence time estimates comes from haplotype networks showing that numerous substitutions accumulated between matrilineal clades preventing connection at the 95\% probability limit (Figure 4). Furthermore, there is considerable variation within most giraffe subspecies that can only develop during considerable time periods. Finally, signs of haplotype sharing between subspecies are rare (Figure 4), suggesting that maternal clades have been separated from each other for a considerable amount of time and that female gene flow among those clades is limited. However, it is not clear if the nine deviating individuals are misidentified samples, or if they result from human translocation or introgression of mtDNA among different giraffe populations. From 26 Masai/Thornicroft's giraffe individuals, two share mtDNA haplotypes with South African giraffe, and one has a unique haplotype similar to reticulated giraffe (Figure 1, Figure 4). Evidence from autosomal microsatellites supports the clear structuring into subspecific groups, although limited signs of allele sharing were found among some populations [9].

Today, the majority of giraffe populations analyzed are widely separated and geographically isolated. This is a consequence of increasing agricultural practices causing habitat loss and fragmentation, of human population and settlement growth, and illegal hunting. Historically, and during the Pleistocene, the distribution ranges may have been more contiguous. Yet, during the Pleistocene, some barriers must have limited female gene flow among different giraffe populations. The distribution of many African ungulates is correlated closely with the distribution of savannah habitat, which in turn is strongly influenced by climatic conditions. The African climate experienced wide changes during the Pleistocene, resulting in recurrent expansions and contractions of savannah habitat and tropical forest. An increase of tropical forest across Central Africa during warm and wet periods (pluvials) around the equator might explain the north-south split seen today in giraffe and other ungulates [32,33]. In the northern parts of the distribution range, the expansion of the Lake Mega-Chad at about 8,000 to 3,000 years ago [34], might have affected recent giraffe dispersal [10].

We dated the divergence between the Angolan and South African giraffe matrilines in Botswana to 1.4 Ma. This deep, early Pleistocene divergence exists despite their close geographic proximity: distances up to $300 \mathrm{~km}$ can be travelled by giraffe [35]. Today, no obvious geographic barrier appears to separate these two subspecies. Thus, we propose a historical "cryptic" rift valley as explanation for the pattern seen in Botswana, as outlined below.

A known geographic boundary follows the Okavango River (Figure 3B) and Gumare Fault in the northwest of Botswana and extends east to the Thamalakhane Fault south of the Okavango pans and the Ntwetwe Pan. The Owambo-Kalahari-Zimbabwe epeirogenic axis (O-K-Z; Figure 3B) also forms a subtle but yet distinct geographic boundary [21,20] between Angolan and South African giraffe populations. Today, this area only holds seasonal water and thus does not seem as an obvious barrier to dispersal. However, it could have been a barrier during the Pleistocene [21,36]. The OkavangoBangweulu axis (O-B; Figure $3 \mathrm{~B}$ ) is the southern extension of the East African Rift System and could have acted as further geographic separator when mountains were lowered and drainage systems formed resulting in the north-east split of giraffe matrilines. The persistence of these conditions might have been reinforced, if an early Pleistocene interglacial coincided with a maximum extent of Palaeo-Lake Makgadikgadi, which ended likely before the Middle Pleistocene ( 970 to $500 \mathrm{ka}$ ) [21,36]. It has been suggested that a "cryptic" rift valley runs northeast to southwest across Botswana from Zambia with faulting ramifying southwest which is represented best by the development of the Fish River canyon in southern Namibia [37]. There were massive lake systems in northeast Botswana, but these dwindled by 500 to 600 ka (Palaeo-Lake Thamalakhane) [21]. Cotterill [36] argues that the above described phylogeographic anomaly is a result of an expansion of moist, evergreen forests in an interglacial, e. g. during warm and wet conditions. Such a "cryptic" rift valley can also explain distributions of other 
animals that are similar to the distribution of giraffe mtDNA haplotypes: African forest elephant (Loxodonta cyclotis) haplotypes are not within the variation of the African elephant (L. africana) from central Namibia (and southeast Botswana), but are confined only to the populations in northern Botswana and northwestern Zambia [12]. Phylogeographic divergences between southeast and northeast representatives of the Damara dikdik (Madoqua damarensis) and the impala (Aepyceros petersi) [38] exhibit both congruent distributions with Angolan giraffe in Namibia, as a result of Pleistocene climatic conditions and/or major changes in the larger rivers on the southcentral African plateau during the Pleistocene [39]. Finally, the estimated population expansion of the Okavango Red lechwes (Kobus leche), a floodplain specialist, is explained by expansion of floodplain habitats following contraction of the northeast Botswana mega-lakes in the Middle Pleistocene [36].

Thus, the persistence of a vast mosaic of aquatic habitats and moist forest occupied the shallow rift valley of northeast Botswana through much of the Pleistocene [21]. This scenario poses a conceivable explanation for the formation of the distribution of Angolan and South African giraffe maternal lineages as currently seen in Botswana. Today, no obvious geographic barrier appears to separate these two subspecies. Ecological or behavioral factors, such as a specific mate recognition system [40], possibly differentiated pelage pattern and female philopatry may maintain limited genetic admixture.

A major episode of aridity in a Pleistocene glacial period may explain mtDNA lineage divergence within Angolan giraffe populations being restricted to Namibia (including Etosha National Park), and one being located in central Botswana (Central Kalahari Game Reserve). Few large mammals show such phylogeographic evidence of strong influence by geological landforms in the form of genetic depauperation or change in the extant distributions across southern Angola, northeastern Botswana and southwestern Zambia [39].

Mitochondrial DNA is maternally inherited from mother to offspring. It allows tracing the maternal lineage and reflects female movements, or the lack thereof, in a phylogeographic context. While we acknowledge the pitfalls of only investigating a small, uniparentally inherited part of the genome [26], mtDNA nevertheless enabled us to specifically analyze the maternal lineages of giraffe subspecies and also include database sequences of reticulated giraffe, for which samples are lacking. Reticulated giraffe are interesting due to their high variability and close proximity to subspecies of the southern clade. Moreover, it has been shown previously that phylogenetic trees based on mtDNA and nuclear microsatellites are congruent in giraffe [9], suggesting that the matrilineal structuring is not differing considerably from that of the species as a whole. The clear structure of the mtDNA clades might thus allow inferring that giraffe populations (and not only the matrilines) have been separated from each other for a considerable amount of time. Alternatively, mtDNA structure might reflect the nature of females to stay at or return to their place of birth (philopatry or site fidelity). Although female philopatry and male-biased dispersal has not been systematically studied in wild giraffe, it is a general pattern in many mammals [41]. However, long-term field observations by one of the authors (JF) support fidelity of both sexes of giraffe to a particular region, because the populations of desertdwelling Angolan giraffe in northwest Namibia remained without contact and genetic admixture for at least five years, despite close proximity to other giraffe in Etosha National Park approximately 150 to $200 \mathrm{~km}$ east. The effects of male-biased gene flow on phylogeographic structuring of a widely distributed species have recently been demonstrated in bears [42]. To further investigate if giraffe represent one species with matrilineal structuring or a multi-species complex, and to analyze the extent of mitochondrial and nuclear discordance [43], future research must incorporate multiple independently inherited autosomal loci. The differences in pelage pattern observed among giraffe from different regions might reflect nuclear variation, indicative of separation between subspecies also at biparentally inherited parts of the genome. Moreover, markers from the paternally inherited Y chromosome would be beneficial to specifically study male gene flow to recover a potentially contrasting structuring of the patriline. If giraffe exhibited male-biased dispersal and if several species were involved, female-specific mtDNA is predicted to be a marker with high introgression rates, showing insufficiently diagnostic resolution on species delimitation [23].

\section{Conclusions}

Enhanced sampling from key regions of the giraffe distribution range show a clear matrilineal structuring of giraffe into distinct clades. The genetic analyses support a clear north-south split, separating two major matrilineal clades in giraffe (southern and northern clade). We also found a sharp east-west delineation between Angolan and South African giraffe, in an area in northern Botswana that has not been genetically investigated before. Our study shows for the first time that South African giraffe are distributed in different parks in Botswana, north of their previously known distribution range. Biparentally and/or paternally inherited sequence markers will be the next step to fully understand the subspecies/species structure in this widespread charismatic African mammal.

\section{Methods}

We collected giraffe tissue samples from seven of nine currently described subspecies (Table 1) (G. c. angolensis, 
G. c. giraffa, G. c. tippelskirchi, G. c. antiquorum, G. c. rothschildi, G. c. peralta, G. c. thornicrofti) and included published data for G. c. reticulata (Additional file 1: Table S1) in our analyses. In August 2009, samples for seven subspecies were collected using remote delivery biopsy darting from free-ranging giraffe in major giraffe populations in northern and central Botswana: Moremi Game Reserve (MGR), Chobe National Park (CNP), Central Kalahari Game Reserve (CKGR) and Nxai Pans (NXP). In 2013, samples were collected from the Vumbura Concession (V) and northern Okavango Delta in Botswana, and from Bwabwata National Park (BNP) in northeastern Namibia (Figure 3). Additional samples were collected in collaboration with conservation partners in Chad, Democratic Republic of Congo, Niger, South Africa, Tanzania and Uganda (Table 1, Additional file 1: Table S1). Skin biopsies were stored at room temperature in a tissue preservative buffer [44] with glutaraldehyde prior to DNA isolation. Whole genomic DNA was extracted from tissue and blood using standard phenol/chloroform extraction [45].

The complete cytb gene and a partial CR were PCR amplified and sequenced with newly designed giraffespecific PCR primers that were constructed from an existing mitochondrial genome of the giraffe [EMBL AP003424]. The 1,140 nt long cytb gene was amplified with the primer pair 5'-TGAAAAACCATCGTTGTC GT-3' and 5'-GTGGAAGGCGAAGAATCG-3' and the control region (422 nt) was amplified with the primer pair 5'-TGAAAAACCATCGTTGTCGT-3' and 5'-GTG GAAGGCGAAGAATCG-3'. In rare cases where amplification or sequencing produced unintelligible sequences or sequences with poor quality, mitochondrial-specific sequences were obtained with an alternative primer pair (5'-GACCCACCAAAATTTAACACAATC-3' and 5'-GT ATGAAGTCTGTGTTGGTCGTTG-3’).

PCR amplification of mtDNA sequences was performed with $10 \mathrm{ng}$ genomic DNA using the VWR Mastermix containing Amplicon-Taq (VWR International $\mathrm{GmbH}$, Darmstadt, Germany) according to the following protocol: $6 \mu \mathrm{L} 2 \times$ mastermix incl. Taq, $0.25 \mu \mathrm{L} 100 \times$ bovine serum albumin, $0.4 \mu \mathrm{L} 10 \mathrm{pmol} / \mu \mathrm{L}$ each forward and reverse primer, $6.45 \mu \mathrm{L}$ desalted water, DNA. PCR conditions for were as follows: initiation at $95^{\circ} \mathrm{C}$ for 5 min, 35 cycles of denaturation (at $95^{\circ} \mathrm{C}$ for $30 \mathrm{~s}$ ), annealing (at $50^{\circ} \mathrm{C}$ for $30 \mathrm{~s}$ ) and elongation (at $72^{\circ} \mathrm{C}$ for $1 \mathrm{~min}$ ), and a final elongation step at $72^{\circ} \mathrm{C}$ for $5 \mathrm{~min}$. The PCR products were diluted in water and cycle sequencing was done with the BigDye terminator sequencing kit 3.1 (Applied Biosystems, Foster City, California). Excess dye was removed with the BigDye XTerminator Purification Kit (Applied Biosystems). Purified products were analyzed on an Applied Biosystems ABI 3730 DNA Analyzer [EMBL: HG975087-HG975290].
Our data set was complemented with published sequences from databases (listed in Additional file 1: Table S1) e.g. from $[9,10,46]$. Sequences were manually edited in Geneious version 5.6.4 (Biomatters, Auckland, New Zealand) and aligned with ClustalX [47]. The corresponding sequences from two okapis (Okapia johnstoni) database samples [EMBL: JN632674, HF571214, HF571175] were used as outgroup.

TCS 1.21 [48] inferred statistical parsimony haplotype networks with the connection probability limit set to $95 \%$. Columns containing ambiguous sites were removed from the alignment and gaps were treated as fifth state. DnaSP 5.10 [49] was used for the calculation of nucleotide diversity, number of haplotypes and haplotype diversity and Arlequin ver 3.5 [50] for pairwise $\mathrm{F}_{\mathrm{ST}}$ values. Inkscape 0.48 was used to improve trees and networks graphics.

For divergence time estimations, mtDNA sequences from suitable ruminants (Pudu puda, Rangifer tarandus, Muntiacus muntjak and Cervus elaphus) were obtained from EMBL/GenBank (Additional file 1: Table S1). The split between Pudu puda and Rangifer tarandus was set to $5 \mathrm{Ma}$ and between Muntiacus muntjak and Cervus elaphus to $9 \mathrm{Ma}$ according to the fossil record [46]. A Bayesian phylogenetic tree including all 161 giraffe individuals and two okapis was estimated in BEAST v1.7.5 [51]. The branch length were calculated on the BEAST tree topology in TREEFINDER version of March 2008 using a maximum likelihood approach [52]. Coalescent based divergence times were estimated in BEAST on a restricted subset of the giraffe individuals in order to avoid an imbalance between taxon sampling of giraffe and outgroups. The subset included one representative of each subspecies and major population. We used the $\mathrm{HKY}+\mathrm{I}+\mathrm{G}$ substitution model as identified best fitting by jModelTest [53], a lognormal relaxed clock with a uniform prior on the substitution rate and ran the program for $2 \times 10^{8}$ generations. Convergence was confirmed in Tracer v1.5.

\section{Availability of supporting data}

DNA sequences are deposited at GenBank under the accession numbers [EMBL: HG975087-HG975290].

\section{Additional file}

Additional file 1: Sample information with locations, accession numbers, and subspecies designation.

\section{Abbreviations}

Cytb: Cytochrome b; CR: Control region; $\mathrm{H}_{\mathrm{d}}$ : Haplotype diversity; ka: Thousand years; KAZA: Kavango-Zambezi; Ma: Million years; mt: Mitochondrial; nt: Nucleotides; numts: Nuclear mitochondrial DNA; O-K-Z epigeiric 
axis: Owambo-Kalahari-Zimbabwe epigeiric axis; O-B axis: Okavango-Bangweulu axis; PCR: Polymerase chain reaction.

\section{Competing interests}

The authors declare that they have no competing interests.

\section{Authors' contributions}

$\mathrm{FB}$ and $\mathrm{TB}$ have done the molecular lab work. FB, TB, and AJ performed the data analysis. AT, AM, FD, and JF obtained the samples. AJ, FB, JF, and TB have written the manuscript. All authors read and approved the final version of the manuscript.

\section{Acknowledgements}

The study was supported by the research funding program "LOEWE Landes-Offensive zur Entwicklung Wissenschaftlich-ökonomischer Exzellenz" of Hesse's Ministry of Higher Education, Research, and the Arts. We appreciate the financial and logistical support from Giraffe Conservation Foundation, Auckland Zoo, Southern African Regional Environmental Program, Mohamed bin Zayed Species Conservation Fund, Wilderness Safaris, Blank Park Zoo, Chester Zoo, Okavango Community Trust, Elephants Without Borders and the University of the Free State, South Africa. The field work would not have been accomplished without in-country support from Stephanie, Luca and Molly Fennessy, Rick Brenneman, Simon Morris, Kylie McQualter, Jean-Patrick "JP" Suraud, Richard Hoare, Pete Morkel, African Parks Foundation and the Mayes and Voges families. We would like to thank Fenton D.P. "Woody" Cotterill and other reviewers for their invaluable insight and comments. Finally, we would like to thank both the Botswana and Namibia Wildlife Authorities for permission and assistance to carry out this research.

\section{Author details}

${ }^{1}$ Biodiversity and Climate Research Centre (BiK-F) - Ecological Genomics \& Senckenberg Gesellschaft für Naturforschung (SGN), Senckenberganlage 25, 60325 Frankfurt am Main, Germany. ${ }^{2}$ Giraffe Conservation Foundation, 26 Grasmere Road, Purley, Surrey CR8 1DU, England. ${ }^{3}$ School of Biological Earth and Environmental Studies (BEES), University of New South Wales (UNSW), Sydney, New South Wales 2052, Australia. ${ }^{4}$ Department Animal, Wildlife \& Grassland Science, University of Free State, Faculty of Natural and Agricultural Sciences, Bloemfontein, South Africa. ${ }^{5}$ Goethe University Frankfurt, Institute for Ecology, Evolution \& Diversity, Biologicum, Max-von-Laue-Straße 13, 60439 Frankfurt am Main, Germany.

Received: 26 September 2014 Accepted: 3 October 2014 Published online: 23 October 2014

\section{References}

1. Fennessy JT: Ecology of desert-dwelling giraffe Giraffa camelopardalis angolensis in northwestern Namibia. In PhD thesis. University of Sydney; 2004.

2. Fennessy J: An overview of Giraffe Giraffa camelopardalis taxonomy, distribution and conservation status, with a Namibian comparative and focus on the Kunene Region, Namibia. J Namib Sci Soc 2008, 56:1-16.

3. Brisson MJ: Regnum animale in classes IX. distributum, sive synopsis methodica sistens generalem Animalium distributionem in classes $I X$, \& duarum primarum classium, Quadrupedum scilicet \& Cetaceorum, particularem divisionem in Ordines, Sectiones, Genera \& Species. Cum brevi cujusque Speciei Descriptione, Citationibus Auctorum de iis tractantium, Nominibus eis ab ipsis \& Nationibus impositis, Nominibusque vulgaribus. Lugduni Baravorum: Apud Theodorum Haak; 1762.

4. Mitchell G, Skinner JD: On the origin, evolution and phylogeny of giraffes Giraffa camelopardalis. Trans Roy Soc S Afr 2003, 58(1):51-73.

5. Lydekker R: On the subspecies of Giraffa camelopardalis. Proc Zool Soc Lond 1904, 74(1):202-229.

6. Dagg Al, Foster JB: The Giraffe: Its Biology, Behavior and Ecology. Malabar: Krieger Publishing Company; 1982.

7. Fennessy J, Brown D: Giraffa camelopardalis. In IUCN Red List of Threatened Species. Version 2014.2. Edited by IUCN. 2010. http://www.iucnredlist.org/ details/9194/0

8. Groves C, Grubb P: Ungulate taxonomy. Baltimore: John Hopkins University Press; 2011.
9. Brown DM, Brenneman R, Koepfli KP, Pollinger J, Mila B, Louis EE Jr, Georgiadis N, Grether G, Wayne RK: Extensive population genetic structure in the giraffe. BMC Bio/ 2007, 5:57-70.

10. Hassanin A, Ropiquet A, Gourmand AL, Chardonnet B, Rigoulet J: Mitochondrial DNA variability in Giraffa camelopardalis: consequences for taxonomy, phylogeography and conservation of giraffes in West and central Africa. C R Biol 2007, 330:265-274.

11. Fennessy J, Bock F, Tutchings A, Brenneman R, Janke A: Mitochondrial DNA analyses show that Zambia's South Luangwa Valley giraffe (Giraffa camelopardalis thornicrofti) is genetically isolated. Afr J Ecol 2013, 51(4):635-640.

12. Roca AL, Georgiadis N, O'Brien SJ: Cytonuclear genomic dissociation in African elephant species. Nat Genet 2005, 37(1):96-100.

13. Brandt AL, Hagos Y, Yacob Y, David VA, Georgiadis NJ, Shoshani J, Roca AL: The elephants of Gash-Barka, Eritrea: Nuclear and mitochondrial genetic patterns. J Hered 2014, 105(1):82-90.

14. Arctander $P$, Johansen $C$, Coutellec-Vreto MA: Phylogeography of three closely related African bovids (tribe Alcelaphini). Mol Biol Evol 1999, 16(12):1724-1739.

15. Osmers B, Petersen BS, Hartl HB, Grobler JB, Kotze A, Van Aswegen E, Zachos FE: Genetic analysis of southern African gemsbok (Oryx gazella) reveals high variability, distinct lineages and strong divergence from the East African Oryx beisa. Mamm Biol 2012, 11(1):60-66.

16. Brenneman RA, Louis EE Jr, Fennessy J: Genetic structure of two populations of the Namibian giraffe, Giraffa camelopardalis angolensis. Afr J Ecol 2009, 47(4):720-728.

17. Namibian Association of Community Based Natural Resource Management (CBNRM) Support Organisations (NACSO): Community conservation in Namibia: a review of communal conservancies, community forests and other CBNRM initiatives. NACSO: Windhoek; 2012

18. Chase M: Dry season fixed-wing aerial survey of elephants and wildlife in northern Botswana. Kasane, Botswana: Elephants Without Borders; 2011.

19. Natural Resource Working Group (NRWG): Game Count in Bwabwata National Park. Windhoek: Unpublished Data; 2012.

20. Moore AE: A reappraisal of epeirogenic flexure axes in southern Africa. S Afr J Geol 1999, 102:363-376.

21. Moore AE, Cotterill FPD, Eckardt FD: The evolution and ages of Makgadikgadi palaeo-lakes: consilient evidence from Kalahari drainage evolution. S Afr J Geol 2012, 115:385-413.

22. Fennessy J, Brenneman R: Giraffa camelopardalis ssp. rothschildi. In IUCN Red List of Threatened Species. Version 2014.2. Edited by IUCN. 2010. http://www.iucnredlist.org/details/174469/0.

23. Petit RJ, Excoffier L: Gene flow and species delimitation. Trends Ecol Evol 2009, 24(7):386-393.

24. Funk DJ, Omland KE: Species-level paraphyly and polyphyly: frequency, causes, and consequences, with insights from animal mitochondrial DNA. Annu Rev Ecol Evol Syst 2003, 34:397-423.

25. Zoological Society of London (ZSL): Part 5: Order Artiodactyla, Suborder: Ruminatia, Infraorder: Pecora, Family: Giraffidae, Genus: Giraffa. Trans Zool Soc London 1965, 30:139-168.

26. Zink RM, Barrowclough GF: Mitochondrial DNA under siege in avian phylogeography. Mol Ecol 2008, 17(9):2107-2121.

27. Harris JM: Family Giraffidae, Koobi Fora Research Project. In The Fossil Ungulates: Geology, Fossil Artiodactyls, and Palaeoenvironments. Oxford: Clarendon Press; 1991:93-138 [Harris JM (Series Editor): The Fossil Ungulates: Geology, Fossil Artiodactyls, and Palaeoenvironments, vol 3].

28. Hailer F, Kutschera VE, Hallström BM, Klassert D, Fain SR, Leonard JA, Arnason U, Janke A: Nuclear Genomic Sequences Reveal that Polar Bears Are an Old and Distinct Bear Lineage. Science 2012, 336(6079):344-347.

29. Won YJ, Hey J: Divergence Population Genetics of Chimpanzees. Mol Biol Evol 2005, 22:297-307.

30. Perini FA, Russo CAM, Schrago CG: The evolution of South American endemic canids: a history of rapid diversification and morphological parallelism. J Evol Biol 2010, 23(2):311-322.

31. Pamilo $P$, Nei M: Relationships between gene trees and species trees. Mol Biol Evol 1988, 5(5):568-583.

32. Vrba ES: The fossil record of African antelopes (Mammalia, Bovidae) in relation to human evolution and paleoclimate. In Paleoclimate and Evolution with emphasis on Human Origins. 1005th edition. Edited by Vrba ES, Denton GH, Partridge TC, Burckle LH. New Haven: Yale University Press; 1995:385-424.

33. Lorenzen ED, Heller R, Siegismund HR: Comparative phylogeography of African savannah ungulates. Mol Ecol 2012, 21:3656-3670. 
34. Leblanc MJ, Leduc C, Stagnitti F, Van Oevelen PJ, Jones C, Mofor LA, Razack M, Favreau G: Evidence for Megalake Chad, north-central Africa, during the Late Quaternary from satellite data. Palaeogeogr Palaeoclimatol Palaeoecol 2006, 230:230-242.

35. Ciofolo I, Le Pendu Y: Seasonal movements of giraffe in Niger. J Trop Ecol 1999, 15(3):341-353.

36. Cotterill FPD: The evolutionary history and taxonomy of the Kobus leche species complex of south-central Africa in the context of palaeodrainage dynamics. In PhD thesis. University of Stellenbosch; 2006.

37. Mvondo F, Dauteuil O, Guillocheau F: The Fish River canyon (Southern Namibia): A record of Cenozoic mantle dynamics? C R Geoscience 2011, 343:478-485.

38. Lorenzen ED, Siegismund HR: No suggestion of hybridization between the vulnerable black-faced impala (Aepyceros melampus petersi) and the common impala (A. m. melampus) in Etosha National Park, Namibia. Mol Ecol 2004, 13(10):3007-3019.

39. Cotterill FPD: Geomorphological influences on vicariant evolution in some African mammals in the Zambezi basin: some lessons for conservation. In Proceedings of an International Symposium on Duiker and Dwarf Antelope in Africa. Edited by Plowman A. Filander Verlag: Fürth; 2003:11-58.

40. Paterson HEH: The recognition concept of species. In Species and speciation. Edited by Vrba ES. Pretoria: Transvaal Museum Monograph; 1985:21-29.

41. Pusey A: Sex-biased dispersal and inbreeding avoidance in birds and mammals. Trends Ecol Evol 1987, 2:295-299.

42. Bidon T, Janke A, Fain SR, Eiken HG, Hagen SB, Saarma U, Hallström BM, Lecomte N, Hailer F: Brown and polar bear Y chromosome reveal extensive male-biased gene flow within brother lineages. Mol Biol Evol 2014, 31(6):1353-1363.

43. Toews DP, Brelsford A: The biogeography of mitochondrial and nuclear discordance in animals. Mol Ecol 2012, 21(16):3907-3930.

44. Seutin G, White BN, Boag PT: Preservation of avian blood and tissue samples for DNA analyses. Can J Zool 1991, 69:82-90.

45. Sambrook J, Fritch EF, Maniatis T: Molecular Cloning: A Laboratory Manual. New York: Cold Spring Harbor; 1989

46. Hassanin A, Delsuc F, Ropiquet A, Hammer C, Jansen Van Vuuren V, Matthee C, Ruiz-Garcia M, Catzeflis F, Areskoug V, Nguyen TT, Couloux A: Pattern and timing of diversification of Cetartiodactyla (Mammalia, Laurasitheria), as revealed by a comprehensive analysis of mitochondrial genomes. C R Biol 2012, 335:32-50

47. Thompson JD, Gibson TJ, Plewniak F, Jeanmougin F, Higgins DG: The ClustalX Windows interface: flexible strategies for multiple sequence alignment aided by quality analysis tools. Nucleic Acids Res 1997, 25:4876-4882

48. Clement M, Posada D, Crandall K: TCS: a computer program to estimate gene genealogies. Mol Ecol 2000, 9(10):1657-1660

49. Librado P, Rozas J: DnaSP v5: A software for comprehensive analysis of DNA polymorphism data. Bioinformatics 2009, 25:1451-1452.

50. Excoffier $L$, Lischer HEL: Arlequin suite ver 3.5: a new series of programs to perform population genetics analyses under Linux and Windows. Mol Ecol Res 2010, 10:564-567.

51. Drummond AJ, Suchard MA, Xie D, Rambaut A: Bayesian phylogenetics with BEAUti and the BEAST 1.7. Mol Biol Evol 2012, 29(8):1969-1973.

52. Jobb G, Von Haeseler A, Strimmer K: TREEFINDER: a powerful graphical analysis environment for molecular phylogenetics. BMC Evol Biol 2004, 4:18.

53. Darriba D, Taboada GL, Doallo R, Posada D: jModelTest 2: more models, new heuristics and parallel computing. Nature Methods 2012, 9(8):772.

doi:10.1186/s12862-014-0219-7

Cite this article as: Bock et al: Mitochondrial sequences reveal a clear separation between Angolan and South African giraffe along a cryptic rift valley. BMC Evolutionary Biology 2014 14:219.

\section{Submit your next manuscript to BioMed Central and take full advantage of:}

- Convenient online submission

- Thorough peer review

- No space constraints or color figure charges

- Immediate publication on acceptance

- Inclusion in PubMed, CAS, Scopus and Google Scholar

- Research which is freely available for redistribution

Submit your manuscript at www.biomedcentral.com/submit
Biomed Central 